\title{
Frey's plus versus Frey's procedure for chronic pancreatitis: Analysis of postoperative outcomes and quality of life
}

\author{
Gunasekaran Gopalakrishnan, Raja Kalayarasan, Senthil Gnanasekaran, and Biju Pottakkat
}

Department of Surgical Gastroenterology, JIPMER, Puducherry, India

\begin{abstract}
Backgrounds/Aims: Additional surgical procedures are often required in patients with chronic pancreatitis (CP) related complications. The present study aims to analyze the type of additional procedures required in patients who underwent Frey's procedure (Frey's plus) and to compare the short-term outcomes and quality of life with patients who underwent only Frey's procedure. Methods: Retrospective analysis of a prospectively maintained database of patients who underwent surgery for CP between January 2012 and February 2018 and completed at least one year of follow-up. Patients who underwent non-Frey's surgical procedures were excluded. Clinical parameters, postoperative pain relief (using Izbicki pain score) and functioning scale score (EORTC QLQ C30) of patients who underwent Frey's plus procedure and only Frey's procedure were compared. Results: Of the 146 patients who underwent surgery for CP during the study period, 100 patients (Frey's procedure-68, Frey's plus procedure-32) were included in this study. Roux-en-Y hepaticojejunostomy was the commonly performed additional procedure $(n=12)$. The demographic and clinical parameters were comparable, except for more patients with jaundice $(28.1 \%$ vs. $2.9 \%, p=0.01)$ and prolonged operative time (374.6 mins vs. 326.3 mins, $p=0.01$ ) in Frey's plus group. However, there was no significant difference in mean intraoperative blood loss, postoperative morbidity or duration of hospital stay. At median (range) follow up of 34 (12-86) months, there was no significant difference in the pain control and quality of life between two groups. Conclusions: Frey's plus procedure for chronic pancreatitis can be safely performed wherever indicated without adversely affecting the postoperative outcome or quality of life. (Ann Hepatobiliary Pancreat Surg 2020;24:496-502)
\end{abstract}

Key Words: Frey's procedure; Frey's plus procedure; Chronic pancreatitis; Surgery

\section{INTRODUCTION}

Chronic pancreatitis (CP) is characterized by progressive and irreversible damage to both exocrine and endocrine components of the pancreas, eventually resulting in significant exocrine insufficiency and diabetes. ${ }^{1}$ Worldwide the main etiology for $\mathrm{CP}$ is chronic alcohol intake, and the most common symptom is chronic abdominal pain. ${ }^{2-4}$ Although medical treatment and endoscopic interventions are primarily offered to patients with $\mathrm{CP}$, approximately $40 \%$ to $75 \%$ will require surgery during their disease course. ${ }^{5}$ The objective of surgery is to relieve intractable pain while preserving pancreatic endocrine and exocrine components. The Frey procedure that combines partial resection of the head of the pancreas (resection) with lateral pancreaticojejunostomy (drainage) is the commonly per- formed surgical procedure. The hybrid procedure improves the overall pancreatic ductal drainage by effectively decompressing main pancreatic duct and relieve compartment syndrome in the head of the pancreas presumed to be the pacemaker for pain. ${ }^{6}$

The inflammatory process related to $\mathrm{CP}$ can result in multiple pancreatic and extrapancreatic complications involving adjacent vascular and luminal structures. Both endoscopic and surgical treatment options are available for most of the CP related complications. In patients undergoing Frey procedure, the spectrum of $\mathrm{CP}$ related complications requiring additional surgical intervention is not well studied. Also, some of the CP related complications like pseudocyst and biliary obstruction can contribute to abdominal pain in these patients. To date, numerous studies have analysed the short and long-term outcomes fol-

Received: April 12, 2020; Revised: July 11, 2020; Accepted: July 12, 2020

Corresponding author: Raja Kalayarasan

Department of Surgical Gastroenterology, Room No. 5442, 4th floor, Superspeciality Block, JIPMER, Puducherry 605006, India Tel: +91-413-2297365, Fax: +91-984-3015499, E-mail: kalayarasanraja@yahoo.com

Copyright (C) 2020 by The Korean Association of Hepato-Biliary-Pancreatic Surgery

This is an Open Access article distributed under the terms of the Creative Commons Attribution Non-Commercial License (http://creativecommons.org/ licenses/by-nc/4.0) which permits unrestricted non-commercial use, distribution, and reproduction in any medium, provided the original work is properly cited. Annals of Hepato-Biliary-Pancreatic Surgery • pISSN: 2508-5778 • elSSN: 2508-5859 
lowing the Frey's procedure and have compared it to other surgical procedures performed for CP. However, the postoperative outcomes and quality of life of patients undergoing Frey's plus procedure defined as Frey's procedure combined with additional surgical procedures for $\mathrm{CP}$ related complications have not been previously reported. The aim of the present study was to analyse the type of additional procedures required in patients who underwent Frey's plus procedure and compare the postoperative outcomes and quality of life of patients with CP undergoing Frey's procedure and Frey's plus procedure.

\section{MATERIALS AND METHODS}

The data was collected from the prospectively maintained database of patients who underwent surgery for CP between January 2012 and February 2018. Patients who underwent Frey's procedure and Frey's plus procedure during the study period and completed at least one year of follow-up were included in the analysis. Patients who underwent lateral pancreatojejunostomy, pancreatoduodenectomy, total pancreatectomy, Beger and Berne procedures for CP were excluded from the analysis. Also, patients who underwent additional procedures for non-CP related pathology along with Frey's procedure were excluded. The study was approved by the Institute scientific advisory and ethics committee.

The preoperative evaluation and indication for Frey's procedure have been previously reported by the authors. ${ }^{7}$ The demographic parameters, clinical presentation, operative parameters, indication for Frey's plus procedure, postoperative hospital stay, 30-day morbidity and mortality were documented. Significant weight loss is defined as more than $10 \%$ weight loss in the preceding 12-month period. As previously reported, CP patients with biliary stricture and persistently elevated bilirubin for more than 4 weeks or progressively increasing serum alkaline phosphatase were considered for biliary drainage. ${ }^{8}$ Choledochoplasty was done in patients in whom the distal bile duct was inadvertently opened during head coring. Cystojejunostomy was performed for CP patients with large extrapancreatic pseudocyst. In patients with splenic vein thrombosis and gastric varices on upper gastrointestinal endoscopy, splenectomy was performed. Postoperative pancreatic fistula and hemorrhage were defined and graded using the criteria recommended by the International Study Group of Pancreatic Surgery. ${ }^{9,10}$ Izbicki pain score designed specifically for CP was used to assess pain. ${ }^{11}$ It consists of two subjective (frequency of pain, the intensity of pain measured using a visual analog score-VAS) and two objective (use of analgesics, and disease-related inability to work) components. The final score obtained by dividing the sum of rank values by four ranges from 0 (no pain) to 100 (severe, debilitating pain). Functioning scale score was measured using the European Organization for Research and Treatment of Cancer Quality of Life Questionnaire (EORTC QLQ C30). ${ }^{11}$ It consists of physical status, working ability, global quality of life, cognitive, emotional and social functioning. The functioning scale score ranges from 0 to 100 , with a higher score representing a higher level of functioning. Postoperative pain score and a functioning scale score of the patients included in this study were evaluated at one year follow up.

Categorical variables were expressed as frequencies and percentages and continuous variables as mean with standard deviation or median with range. Continuous data were analyzed using the Chi-square test and student t-test. Non-normal distributed data were analyzed using the Mann Whitney $\mathrm{U}$ test. A value of $p<0.05$ was considered significant. Data were analyzed using Statistical Package for the Social Sciences version 19.0 (SPSS, Chicago, IL, USA).

\section{RESULTS}

During the study period, 146 patients underwent surgery for CP. Of these, 46 patients were excluded from the study as they underwent non-Frey's surgical procedure $(\mathrm{n}=38)$; Frey's procedure combined with additional surgical procedures for non-CP related pathology $(n=2)$; underwent Frey's procedure but not available for pain score and functioning scale score evaluation at one year follow up $(n=6)$. Sixty-eight patients who underwent Frey's procedure and 32 patients who underwent Frey's plus procedure were included in the study. The demographic and clinical parameters of patients in two groups were comparable except for more patients with jaundice and significant weight loss in the Frey's plus group (Table 1).

In the Frey's plus group Roux-en-Y hepaticojejunostomy was the commonly performed additional surgical proce- 
dure followed by distal pancreatosplenectomy (Table 2). Of the 12 patients who underwent Roux-en-Y hepaticojejunostomy in the Frey's plus group, eight patients had persistently elevated bilirubin for more than four weeks. Progressive increase in alkaline phosphatase was the indication for biliary drainage in the other four patients. A repair of the gastric fistula was done in one patient with pancreatogastric fistula and hemosuccus pancreaticus. Dismantling of pancreatojejunostomy, revision Frey's proce-

Table 1. Demographic and clinical parameters of patients who underwent Frey's procedure and Frey's plus procedure

\begin{tabular}{|c|c|c|c|}
\hline Parameter & $\begin{array}{l}\text { Frey's } \\
\text { procedure } \\
(\mathrm{n}=68)\end{array}$ & $\begin{array}{l}\text { Frey's plus } \\
\text { procedure } \\
(n=32)\end{array}$ & $\begin{array}{c}p \\
\text { value }\end{array}$ \\
\hline Age, mean (SD) & $35.5(12.6)$ & 39.9 (14) & 0.11 \\
\hline \multicolumn{4}{|l|}{ Sex, n (\%) } \\
\hline Female & $20(29.4)$ & $5(15.6)$ & 0.14 \\
\hline Male & $48(70.6)$ & $27(84.4)$ & \\
\hline \multicolumn{4}{|l|}{ Symptoms, n (\%) } \\
\hline Pain abdomen & $68(100)$ & $32(100)$ & 1.00 \\
\hline Vomiting & $28(41.2)$ & $11(34.4)$ & 0.52 \\
\hline Weight loss & $10(14.7)$ & $11(34.4)$ & 0.02 \\
\hline Jaundice & $2(2.9)$ & $9(28.1)$ & 0.01 \\
\hline $\begin{array}{l}\text { Duration of } \\
\text { symptoms in months, } \\
\text { median (range) }\end{array}$ & $21(12-58)$ & $27(13-49)$ & 0.44 \\
\hline \multicolumn{4}{|l|}{ Etiology, n (\%) } \\
\hline Alcoholic & $30(44.1)$ & $16(50)$ & 0.58 \\
\hline Non-alcoholic & $38(55.9)$ & $16(50)$ & \\
\hline $\begin{array}{l}\text { Preoperative pain score, } \\
\text { mean (SD) }\end{array}$ & $77.4(5.8)$ & $75.0(7)$ & 0.08 \\
\hline $\begin{array}{l}\text { Exocrine insufficiency, } \\
\text { n (\%) }\end{array}$ & $13(19.1)$ & $7(21.9)$ & 0.95 \\
\hline $\begin{array}{l}\text { Endocrine insufficiency, } \\
\text { n }(\%)\end{array}$ & $32(47.1)$ & $10(32.0)$ & 0.12 \\
\hline
\end{tabular}

dure with gastrojejunostomy was done in one patient who presented with chronic abdominal pain and recurrent vomiting two years after lateral pancreatojejunostomy done elsewhere for CP. Of the seven patients with left-sided portal hypertension, one patient had a history of hematemesis that was managed by endoscopic glue injection of gastric varices. The remaining six patients had asymptomatic gastric varices. In the Frey's group, of the 68 patients, 21 patients had deranged liver function test (LFT), 17 patients had intrapancreatic pseudocyst and splenic vein thrombosis in one patient. Of the 21 patients with abnormalities of the LFT, 19 had isolated nonprogressive elevation of alkaline phosphatase, and two patients had transient jaundice. Seventeen patients had one or more intrapancreatic pseudocyst that was incorporated in the pancreatojejunal anastomosis during Frey's procedure without the need for separate cystojejunostomy. One patient had splenic vein thrombosis without signs of left-sided portal hypertension like gastric varices. The perioperative parameters were comparable except for the prolonged operative time in Frey's plus group (Table 3). Surgical site infection was the most common postoperative complication and the postoperative morbidity was comparable between two groups. There was no postoperative mortality.

At a median (range) follow-up of 34 (12-86) months there was no significant difference in the pain score between two groups (Table 4). Also, physical status, ability to work, global quality of life, cognitive functioning, emotional functioning, social functioning, and were comparable between the two groups. On comparison of 28 patients in Frey's group with deranged LFT $(n=10)$, pseudo-

Table 2. Indication and type of additional surgical procedure in Frey's plus group $(n=32)$

\begin{tabular}{|c|c|c|c|}
\hline S. No & Additional surgical procedure performed & Indication for the additional surgical procedure & $\begin{array}{l}\text { Number of } \\
\text { patients }\end{array}$ \\
\hline 1 & Roux-en-Y hepaticojejunostomy & Distal biliary stricture & 12 \\
\hline 2 & Roux-en-Y cystojejunostomy* & Peripancreatic pseudocyst & 8 \\
\hline 3 & Distal pancreatosplenectomy $^{\dagger}$ & $\begin{array}{l}\text { Splenic vein thrombosis, } \\
\text { left sided portal hypertension }\end{array}$ & 7 \\
\hline 4 & $\begin{array}{l}\text { Distal pancreatosplenectomy with } \\
\text { excision of splenic artery pseudoaneurysm }\end{array}$ & Splenic artery pseudoaneurysm & 2 \\
\hline 5 & Gastrojejunostomy & Gastric outlet obstruction & 2 \\
\hline 6 & Choledochoplasty & $\begin{array}{l}\text { Intrapancreatic portion of common bile duct } \\
\text { inadvertently opened during Frey's procedure }\end{array}$ & 1 \\
\hline
\end{tabular}

\footnotetext{
*Combined with repair of pancreatogastric fistula in one patient and cholecystectomy in one patient

${ }^{\dagger}$ Combined with cholecystectomy in three patients

${ }^{\ddagger}$ Combined with cholecystectomy in one patient
} 
Table 3. Perioperative parameters of patients who underwent Frey's procedure and Frey's plus procedure

\begin{tabular}{lcrc}
\multicolumn{1}{c}{ Parameter } & $\begin{array}{c}\text { Frey's procedure } \\
(\mathrm{n}=68)\end{array}$ & $\begin{array}{r}\text { Frey's plus procedure } \\
(\mathrm{n}=32)\end{array}$ & $p$ value \\
\hline Operative time (min), mean (SD) & $326.3(44.5)$ & $374.6(65.7)$ & 0.01 \\
Blood loss (ml), mean (SD) & $251.8(56.8)$ & $290(107.9)$ & 0.07 \\
Blood transfusion, n (\%) & $1(1.5)$ & $2(6.2)$ & 0.24 \\
Commencement of oral semisolids (days), mean (SD) & $2.5(0.8)$ & $2.6(1.3)$ & 0.73 \\
Postoperative morbidity, n (\%) & & $3(9.4)$ & 0.21 \\
Surgical site infection & $3(4.4)$ & $2(6.2)$ & \\
Postoperative pancreatic fistula & $1(1.5)$ & $1(3.1)$ & \\
Postpancreatectomy hemorrhage & $0(0)$ & $1(3.1)$ & \\
Delayed gastric emptying & $1(1.5)$ & $1(3.2)$ & \\
Paralytic ileus & $2(2.9)$ & $0(0)$ & \\
Urinary tract infection & $0(0)$ & $6.3(2.9)$ & 0.34 \\
Bile leak & $5.9(1.6)$ &
\end{tabular}

Table 4. Postoperative pain (Izbicki pain score) and functioning scale (EORTC QLQ C30) score in patients who underwent Frey's procedure and Frey's plus procedure

\begin{tabular}{|c|c|c|c|}
\hline Parameter & $\begin{array}{l}\text { Frey's procedure } \\
\qquad(\mathrm{n}=68)\end{array}$ & $\begin{array}{l}\text { Frey's plus procedure } \\
\qquad(\mathrm{n}=32)\end{array}$ & $p$ value \\
\hline \multicolumn{4}{|l|}{ Izbicki pain score } \\
\hline VAS (visual analog scale), median (range) & $10(0-25)$ & $10(0-20)$ & 0.59 \\
\hline Frequency of pain attacks, median (range) & $0(0-25)$ & $0(0-25)$ & 0.98 \\
\hline Analgesic medication, median (range) & $0(0-15)$ & $0(0-15)$ & 0.79 \\
\hline Inability to work, median (range) & $0(0-50)$ & $0(0-50)$ & 0.88 \\
\hline Pain score, median (range)* & $2.5(0-17.5)$ & $5(2.5-15.3)$ & 0.42 \\
\hline \multicolumn{4}{|l|}{ Functioning scale (EORTC QLQ C30) score $^{\dagger}$} \\
\hline Physical status, median (range) & $90(70-100)$ & $90(60-100)$ & 0.96 \\
\hline Working ability, median (range) & $100(50-100)$ & $90(60-100)$ & 0.89 \\
\hline Cognitive functioning, median (range) & $90(80-100)$ & $90(70-100)$ & 0.92 \\
\hline Emotional functioning, median (range) & $85(65-90)$ & $82.5(55-90)$ & 0.95 \\
\hline Social functioning, median (range) & $85(54-95)$ & $85(65-94)$ & 0.93 \\
\hline Global quality of life, median (range) & $85(65-96)$ & $80(60-90)$ & 0.17 \\
\hline
\end{tabular}

*The pain score was defined as the sum of the rank values of the four criteria divided by four. It ranges from 0 (no pain) to 100 (severe, debilitating pain)

${ }^{\dagger}$ Score ranges from 0 to 100 , with a higher score representing a higher level of functioning

cyst $(n=6)$, splenic vein thrombosis $(n=1)$ or both pseudocyst and deranged LFT ( $\mathrm{n}=11)$ with 32 patients in the Frey's plus group, there was no significant difference $(p>$ $0.05)$ in the perioperative outcomes, postoperative pain score and functioning scale score. In the Frey's group, of the 21 patients with deranged LFT, one patient developed choledocholithiasis secondary to lower CBD stricture. As the endoscopic intervention failed, the patient underwent hepaticojejunostomy 26 months after the initial Frey's procedure. All the 17 patients with pseudocyst incorporated in the pancreatojejunal anastomosis in the Frey's group did not have recurrent pseudocyst in the follow-up.
One patient with splenic vein thrombosis in the Frey's group did not develop gastric varices in the follow-up, and there was partial recanalization of the splenic vein.

\section{DISCUSSION}

The results of the present study suggest that singlestage surgical management of CP related complications do not increase the morbidity of Frey's procedure. While abdominal pain is the most common symptom, during the disease progression, many CP patients develop complications like pseudocyst, biliary stricture, gastric outlet obstruc- 
tion. A pseudocyst is generally considered as the most common complication of $\mathrm{CP} .^{12}$ However, the biliary stricture is the most common complication requiring Frey's plus procedure in the present study. It could reflect the shift in the first line of management of pseudocyst using an endoscopic approach. ${ }^{12,13}$ Pseudocysts associated with CP rarely undergo spontaneous resolution due to associated ductal pathology. ${ }^{12-14}$ Intrapancreatic pseudocysts and pseudocysts $<4 \mathrm{~cm}$ were often associated with spontaneous resolution. ${ }^{14}$ Also, these pseudocysts do not require additional drainage procedures and are usually incorporated in the pancreatojejunal anastomosis during Frey's procedure. In the present series, 17 patients in the Frey's group had one or more intrapancreatic pseudocyst incorporated in the pancreatojejunal anastomosis without any recurrence in the follow-up period. All eight patients in the Frey's plus group who required Roux-en-Y cystojejunostomy had large extrapancreatic pseudocyst. The long-term resolution rate of pseudocysts in $\mathrm{CP}$ using the endoscopic approach is variable, as most of the series have included patients with both acute pancreatitis and $\mathrm{CP}$. The recurrence rate of up to $30 \%$ has been reported with the endoscopic approach for pseudocyst in $\mathrm{CP} .{ }^{12}$ In patients requiring surgery for CP, Frey's plus procedure offers a definitive treatment option compared to the endoscopic management of pseudocyst.

Benign biliary obstruction secondary to bile duct stricture is a common complication in CP patients with an incidence ranging from 3 to $46 \%$, depending on the clinical presentation. ${ }^{15,16}$ In the present series, Roux-en-Y hepaticojejunostomy in the Frey's plus group, was done for patients with persistently elevated bilirubin or progressive increase in alkaline phosphatase. As previously reported, transient jaundice ( $<4$ weeks duration) and asymptomatic nonprogressive rise in alkaline phosphatase $(<3$ times the upper limit) are generally not considered as an indication for biliary drainage even in patients planned for surgical management of $\mathrm{CP}{ }^{8}$ In the present series, of the 21 patients in Frey's group with evidence of bile duct obstruction in the form of transient jaundice or nonprogressive rise in alkaline phosphatase, only one patient required intervention in the follow-up period. With the advancements in the endoscopic biliary drainage, multiple plastic stents and fully covered self-expanding metallic stents are increasingly used for the management of biliary stricture. ${ }^{17,18}$
Although they have superior short-term results compared to the single plastic stent, the long-term success rate drops to $70 \%$. Hence, the use of stents as definitive management for the $\mathrm{CP}$ related biliary stricture is not endorsed by many of the consensus guidelines and its use should be restricted to patients with cholangitis or those who are unfit for surgical intervention., ${ }^{8,19}$ Although both choledochojejunostomy and hepaticojejunostomy provide adequate biliary drainage, the latter is preferred in patients undergoing Frey's procedure. ${ }^{8,20}$ As evident from the present study use of the same Roux limb does not increase the postoperative morbidity and provides effective biliary drainage even in patients with long bile duct stricture and associated duodenal obstruction.

Vascular complications in CP, although rare, are difficult to treat and are responsible for significant morbidity and mortality. Pseudoaneurysm of the splenic, pancreatoduodenal or gastroduodenal artery is the most common arterial complication. ${ }^{21}$ With the advancements in non-surgical intervention, surgery as a primary treatment for pseudoaneurysm is reserved for hemodynamically unstable patients and those who fail non-surgical intervention. ${ }^{22}$ In the present series both the patients in the Frey's plus group underwent preoperative coil embolization for control of bleeding followed by definitive surgical management. Definitive surgical management of pseudoaneurysm is preferred even in $\mathrm{CP}$ patients without significant pancreatic symptoms as continuous exposure to pancreatic juice increase the risk of rebleeding. ${ }^{23,24}$ In both the patients as pseudoaneurysm involved distal splenic artery distal pancreatosplenectomy was performed as part of Frey's plus procedure. For pancreatic head pseudoaneurysm located in the pseudocyst wall, a transcystic approach to the pseudoaneurysm (endoaneurysmorraphy) is preferred. Transductal approach is used for intraparenchymal pseudoaneurysms in the head of pancreas. ${ }^{23,24}$

Splenic vein thrombosis with left-sided portal hypertension is the most common venous complication. ${ }^{25} \mathrm{Al}$ though splenectomy cures left-sided portal hypertension endoscopic glue injection is the first-line treatment for symptomatic gastric varices especially in patients without significant pancreatic symptoms. ${ }^{26}$ However, in CP patients planned for surgical management splenectomy is the treatment of choice for symptomatic gastric varices. ${ }^{27-29}$ In patients with asymptomatic gastric varices, the role of 
splenectomy is controversial even in patients planned for surgical management of CP. However, in the present series, six patients with asymptomatic gastric varices also underwent splenectomy as studies have reported $8-33 \%$ risk of bleeding from the gastric varices in patients who did not undergo splenectomy. ${ }^{27-29}$ While it can be argued that those bleeding episodes in the postoperative period could be effectively controlled by glue injection the results of the present study suggest that Frey's plus procedure does not significantly increase the postoperative complications in this group of patients. With the advancements in energy devices and vascular staplers, the safety of splenectomy is improved in this group of patients.

Surgical intervention for CP is widely accepted as the most effective therapeutic option for control of pain and management of complications. ${ }^{19}$ In recent years there has been a shift from resectional procedures like pancreatoduodenectomy to Beger and Frey's procedure due to equivalent pain relief and favorable postoperative quality of life with the organ-preserving hybrid procedures. ${ }^{19,30}$ Better pain control and quality of life reported in the present study might be due to early surgery. Ke et al. ${ }^{31}$ reported that patients who underwent surgery within 3 years of diagnosis had better pain relief and preservation of pancreatic exocrine and endocrine function. In the present series median interval between onset of symptoms and surgery is less than 28 months in both the groups.

$\mathrm{CP}$ is one of the few benign diseases that require multidisciplinary team management, including gastroenterologists, radiologists and surgeons. As most of the complications of CP could be managed by both endoscopic and surgical approaches, the best approach for an individual patient should be decided by the full consensus of the multidisciplinary team. The results of the present study could help the surgeons and gastroenterologists to choose the right approach in CP patients planned for surgical management. The limitations of the present study are its retrospective nature and a small number of patients in the Frey's plus group. Also, a different type of additional procedures was included in the Frey's plus group. Despite the retrospective analysis, all the data including the pain score and quality of life assessment were collected in a prospectively maintained database. Also, this is the first study to report and compare the postoperative outcomes and quality of life of patients undergoing Frey's and
Frey's plus procedure. Despite more severe disease in Frey's plus group, the perioperative outcomes were comparable to Frey's group except for the prolonged operative time in the Frey's plus group. The results of the present study suggest that biliary stricture, pseudocyst and vascular complications are the most common indications for Frey's plus procedure in CP patients. Frey's plus procedure for $\mathrm{CP}$ can be safely performed wherever indicated without adversely affecting the postoperative outcome. Pain relief and quality of life with Frey's plus procedure are comparable to Frey's procedure.

\section{ACKNOWLEDGEMENTS}

We thank Dr K Vijay Chavada, Associate Professor, Department of community medicine, Indra Gandhi Medical college and Research Institution, Puducherry for assisting with the statistical analysis.

\section{CONFLICT OF INTEREST}

The authors have declared no conflict of interest.

\section{ORCID}

\author{
Gunasekaran Gopalakrishnan: \\ https://orcid.org/0000-0003-0600-4371 \\ Raja Kalayarasan: https://orcid.org/0000-0003-4056-8672 \\ Senthil Gnanasekaran: \\ https://orcid.org/0000-0002-8639-5423 \\ Biju Pottakkat: https://orcid.org/0000-0002-8474-0270
}

\section{AUTHOR CONTRIBUTIONS}

Conceptualization: GG, RK, SG, BP. Data curation: GG, RK, SG. Formal analysis: GG, RK. Funding acquisition: Nil. Methodology: GG, RK, BP. Project administration: RK, BP. Visualization: GG, RK. Writing - original draft: GG, RK. Writing - review \& editing: GG, RK, SG, BP.

\section{REFERENCES}

1. Witt H, Apte MV, Keim V, Wilson JS. Chronic pancreatitis: challenges and advances in pathogenesis, genetics, diagnosis, and therapy. Gastroenterology 2007;132:1557-1573. 
2. Evans JD, Wilson PG, Carver C, Bramhall SR, Buckels JA, Mayer AD, et al. Outcome of surgery for chronic pancreatitis. Br J Surg 1997;84:624-629.

3. Secknus R, Mössner J. [Changes in incidence and prevalence of acute and chronic pancreatitis in Germany]. Chirurg 2000;71: 249-252. German.

4. Ni Q, Yun L, Roy M, Shang D. Advances in surgical treatment of chronic pancreatitis. World J Surg Oncol 2015;13:34.

5. Roch A, Teyssedou J, Mutter D, Marescaux J, Pessaux P. Chronic pancreatitis: a surgical disease? Role of the Frey procedure. World J Gastrointest Surg 2014;6:129-135.

6. Frey CF, Smith GJ. Description and rationale of a new operation for chronic pancreatitis. Pancreas 1987;2:701-707.

7. Pavankumar V, Kalayarasan R, Gnanasekaran S, Pottakkat B. The drain fluid amylase level on the first postoperative day predicts pancreatic fistula in chronic pancreatitis patients undergoing Frey procedure. Ann Hepatobiliary Pancreat Surg 2019; 23:397-402.

8. Saluja SS, Kalayarasan R, Mishra PK, Srivastava S, Chandrasekar S, Godhi S. Chronic pancreatitis with benign biliary obstruction: management issues. World J Surg 2014;38:2455-2459.

9. Bassi C, Marchegiani G, Dervenis C, Sarr M, Abu Hilal M, Adham M, et al. The 2016 update of the International Study Group (ISGPS) definition and grading of postoperative pancreatic fistula: 11 years after. Surgery 2017;161:584-591.

10. Wente MN, Veit JA, Bassi C, Dervenis C, Fingerhut A, Gouma $\mathrm{DJ}$, et al. Postpancreatectomy hemorrhage (PPH): an International Study Group of Pancreatic Surgery (ISGPS) definition. Surgery 2007;142:20-25.

11. Bloechle C, Izbicki JR, Knoefel WT, Kuechler T, Broelsch CE. Quality of life in chronic pancreatitis--results after duodenumpreserving resection of the head of the pancreas. Pancreas 1995; 11:77-85.

12. Udd M, Kylänpää L, Kokkola A. The role of endoscopic and surgical treatment in chronic pancreatitis. Scand J Surg 2020; 109:69-78.

13. Dumonceau JM, Delhaye M, Tringali A, Arvanitakis M, Sanchez-Yague A, Vaysse T, et al. Endoscopic treatment of chronic pancreatitis: European Society of Gastrointestinal Endoscopy (ESGE) guideline- updated August 2018. Endoscopy 2019; 51:179-193.

14. Gouyon B, Lévy P, Ruszniewski P, Zins M, Hammel P, Vilgrain $\mathrm{V}$, et al. Predictive factors in the outcome of pseudocysts complicating alcoholic chronic pancreatitis. Gut 1997;41:821-825.

15. Wisløoff F, Jakobsen J, Osnes M. Stenosis of the common bile duct in chronic pancreatitis. Br J Surg 1982;69:52-54.

16. Abdallah AA, Krige JE, Bornman PC. Biliary tract obstruction in chronic pancreatitis. HPB (Oxford) 2007;9:421-428.

17. Dumonceau JM, Tringali A, Papanikolaou IS, Blero D, Mangiavillano B, Schmidt A, et al. Endoscopic biliary stenting: indica- tions, choice of stents, and results: European Society of Gastrointestinal Endoscopy (ESGE) clinical guideline- updated October 2017. Endoscopy 2018;50:910-930.

18. Siriwardana HP, Siriwardena AK. Systematic appraisal of the role of metallic endobiliary stents in the treatment of benign bile duct stricture. Ann Surg 2005;242:10-19.

19. Kempeneers MA, Issa Y, Ali UA, Baron RD, Besselink MG, Büchler $\mathrm{M}$, et al. International consensus guidelines for surgery and the timing of intervention in chronic pancreatitis. Pancreatology 2020;20:149-157.

20. Vijungco JD, Prinz RA. Management of biliary and duodenal complications of chronic pancreatitis. World J Surg 2003;27:12581270.

21. Verde F, Fishman EK, Johnson PT. Arterial pseudoaneurysms complicating pancreatitis: literature review. J Comput Assist Tomogr 2015;39:7-12.

22. Gabrielli D, Taglialatela F, Mantini C, Giammarino A, Modestino F, Cotroneo AR. Endovascular treatment of visceral artery pseudoaneurysms in patients with chronic pancreatitis: our singlecenter experience. Ann Vasc Surg 2017;45:112-116.

23. Bender JS, Bouwman DL, Levison MA, Weaver DW. Pseudocysts and pseudoaneurysms: surgical strategy. Pancreas 1995;10:143147.

24. El Hamel A, Parc R, Adda G, Bouteloup PY, Huguet C, Malafosse M. Bleeding pseudocysts and pseudoaneurysms in chronic pancreatitis. Br J Surg 1991;78:1059-1063.

25. Xu W, Qi X, Chen J, Su C, Guo X. Prevalence of splanchnic vein thrombosis in pancreatitis: a systematic review and metaanalysis of observational studies. Gastroenterol Res Pract 2015; 2015:245460

26. Ramesh H, Jacob G, Venugopal A, Lekha V, Jacob M. Surgical management of chronic pancreatitis with portal hypertension--a 19-year experience. Surgery 2008;143:252-258.

27. Bradley EL 3rd. The natural history of splenic vein thrombosis due to chronic pancreatitis: indications for surgery. Int $\mathrm{J}$ Pancreatol 1987;2:87-92.

28. Loftus JP, Nagorney DM, Ilstrup D, Kunselman AR. Sinistral portal hypertension. Splenectomy or expectant management. Ann Surg 1993;217:35-40.

29. Agarwal AK, Raj Kumar K, Agarwal S, Singh S. Significance of splenic vein thrombosis in chronic pancreatitis. Am J Surg 2008;196:149-154.

30. Farkas G, Leindler L, Daróczi M, Farkas G Jr. Prospective randomised comparison of organ-preserving pancreatic head resection with pylorus-preserving pancreaticoduodenectomy. Langenbecks Arch Surg 2006;391:338-342.

31. Ke N, Jia D, Huang W, Nunes QM, Windsor JA, Liu X, et al. Earlier surgery improves outcomes from painful chronic pancreatitis. Medicine (Baltimore) 2018;97:e0651. 